See discussions, stats, and author profiles for this publication at: https://www.researchgate.net/publication/337739048

\title{
Disposition-Content Congruency in Adolescents' Alcohol-Related Social Media (Self-) Effects: The Role of the Five-Factor Model
}

Article in Journal of Studies on Alcohol and Drugs · November 2019 Dol: 10.15288/jsad.2019.80.631

\section{CITATIONS}

5 authors, including:

Femke Geusens

KU Leuven

14 PUBLICATIONS 80 CITATIONS

SEE PROFILE

Wendy Van Lippevelde

Universitetet i Agder

86 PUBLICATIONS 2,035 CITATIONS

SEE PROFILE
READS

40

Leentje Vervoort

Radboud University

65 PUBLICATIONS 494 CITATIONS

SEE PROFILE

Kathleen Beullens

KU Leuven

65 PUBLICATIONS 769 CITATIONS

SEE PROFILE

Some of the authors of this publication are also working on these related projects:

Project Anxiety in children View project

Project \#DrinksWithFriends: The underlying processes and conditionality of alcohol-related social media effects View project 
Author postprint version.

Article published in Journal of Studies on Alcohol and Drugs:

https://www.jsad.com/

This article may not exactly replicate the final version published in Journal of Studies on

Alcohol and Drugs. It is not the version on record and is therefore not suitable for citation.

Please refer to the published article for citation:

https://doi.org/10.15288/jsad.2019.80.631

Disposition-Content Congruency in Adolescents' Alcohol-Related Social Media (Self-)

Effects: The Role of the Five Factor Model

$$
\begin{gathered}
\text { Femke Geusens }{ }^{1}, \mathrm{PhD} \\
\text { Jolien Vangeel }{ }^{2}, \mathrm{PhD} \\
\text { Leentje Vervoort }{ }^{3}, \mathrm{PhD} \\
\text { Wendy Van Lippevelde }{ }^{4,5}, \mathrm{PhD} \\
\text { Kathleen Beullens }{ }^{1}, \mathrm{PhD}
\end{gathered}
$$

${ }^{1}$ Leuven School for Mass Communication Research, KU Leuven, Belgium

${ }^{2}$ Department of Business Studies and Business Administration, Karel de Grote Hogeschool, Belgium

${ }^{3}$ Department of Developmental, Personality, and Social Psychology, Ghent University, Belgium

${ }^{4}$ Department of Public Health, Ghent University, Belgium

${ }^{5}$ Department of Public Health, Sport and Nutrition, University of Agder, Norway

\section{Corresponding author}

Femke Geusens

Parkstraat 45 (bus 3603)

B-3000 Leuven

Belgium

femke.geusens@kuleuven.be

Tel: +32163792 38

\section{Funding}

This work was supported by a VLAIO grant (IWT.120054). 
Abstract

Purpose. Accumulating evidence indicates that social networking sites play an increasingly important role in young people's drinking behavior. The present study adds to this line of research by assessing the conditionality of the relationships between exposure to and selfsharing of alcohol-related content on social media and adolescents' drinking behavior. Specifically, the moderating role of the five factor model of personality is determined. Methods. A cross-sectional survey study was conducted among 866 mid-adolescents $\left(\mathrm{M}_{\text {subsample }}=14.85\right.$ years, $\mathrm{SD}=.71,57.5 \%$ girls $)$. Polynomial regression analyses with response surface modeling was used to test the interactions. Results. The findings showed that exposure, but not self-sharing, was directly associated with more alcohol consumption. However, it appeared that the act of sharing was more important than the frequency of sharing. Next, the relationship between exposure and consumption was not found to be moderated by personality. In contrast, there were significant linear and non-linear interactions between self-sharing and all five personality traits. Individuals who are predisposed to engage in more alcohol consumption experience a stronger association between self-sharing and their drinking behavior. Conclusions. Social media can play a role in adolescents' drinking behavior, but this role is partially dependent on temperamental predispositions.

Keywords: Alcohol, social media, adolescents, social media self-effects, neuroticism, agreeableness, conscientiousness, extraversion, openness, five factor model 
BIG FIVE IN ALCOHOL-RELATED SOCIAL MEDIA EFFECTS

Disposition-Content Congruency in Adolescents' Alcohol-Related Social Media (Self-)

Effects: The Role of the Five Factor Model

Most youth start experimenting with alcohol during adolescence (WHO, 2014). In Belgium, the legal drinking age is 16, but the average age of onset is 14 (Melis et al., 2016). Further, adolescents are among the most vulnerable to alcohol-related harm (WHO, 2014). Consequently, it is crucial to improve understanding of the factors contributing to adolescents' alcohol consumption. Biological, psychological, social and cultural factors all play a role in drinking behavior (Skewes and Gonzalez, 2013), with social factors gaining in importance during adolescence (Steinberg, 2008). Adolescents are especially responsive to peer influences, and with the rise of social networking sites (SNS), these social factors are increasingly present online (Moreno, Kota, et al., 2013).

Although few content analytical studies have been conducted among adolescents, content analyses of both European and American students and adults' social media profiles indicate that a large proportion of these profiles refer to alcohol consumption (Beullens and Schepers, 2013; Moreno et al., 2010). Media effects research has been conducted among both adolescents and older samples, demonstrating that the more alcohol references someone self-shares on SNS, the more likely they are to engage in heavy drinking behavior (D'Angelo et al., 2014; Geusens and Beullens, 2017a, 2018; Moreno, Kacvinsky, et al., 2013). These alcohol references simultaneously stem from prior drinking behavior and affect subsequent consumption (Geusens and Beullens, 2017a, 2017b, 2019). Moreover, exposure to references from others is associated with more positive alcohol cognitions and increased (heavy) drinking behavior as well (Beullens and Vandenbosch, 2016; Geusens and Beullens, 2018; Litt and Stock, 2011).

Nevertheless, many recent media effects models and theories argue that as some individuals are more responsive to media than others, it is important to systematically examine non-media 
BIG FIVE IN ALCOHOL-RELATED SOCIAL MEDIA EFFECTS

variables as moderators of media effects (Krcmar, 2009; Oliver and Krakowiak, 2009; Slater, 2007; Slater et al., 2003; Valkenburg and Peter, 2013). Therefore, to offer a clearer understanding of reality and to increase ecological validity of the results, the present study will analyze the conditionality of alcohol-related social media effects, while assessing the exposure and self-sharing pathways side by side.

In this study, the specific conditionality variable that will be focused on is personality. The predominant way to understand personality is the five factor model (FFM) which distinguishes five main personality factors (Costa and McCrae, 1992; Widiger, 2016). Neuroticism reflects the tendency to experience negative affect and emotions, and a sensitivity to potential threat, frustration or loss (Tackett and Lahey, 2016). Extraversion reflects the tendency to experience positive affect, to be assertive, and to desire social attention (Wilt and Revelle, 2016). Openness to experience reflects intellect, culture, imagination and unconventionality (Sutin, 2015), and agreeableness is the tendency or motivation to maintain positive relations with others (Graziano and Tobin, 2016). Finally, conscientiousness reflects the tendency to be self-controlled, responsible towards others, hardworking, orderly and rule abiding (Jackson and Roberts, 2015).

The FFM has been previously associated with a numerous important life outcomes including drinking behavior (Hong and Paunonen, 2009a; Ibáñez et al., 2010; Malouff et al., 2007; Mellos et al., 2010). Specifically, low conscientiousness, high neuroticism, low agreeableness and high extraversion have each repeatedly been found to predict future alcohol use and misuse (Hong and Paunonen, 2009b; Ibáñez et al., 2010; Malouff et al., 2007; Mellos et al., 2010). The role of openness to experience is less clear, but it appears that adolescents with high levels of openness who are on the threshold of trying alcohol for the first time may be more inclined to do so (Malouff et al., 2007). 
BIG FIVE IN ALCOHOL-RELATED SOCIAL MEDIA EFFECTS

These personality traits can not only play a direct role in predicting adolescents' alcohol consumption, but affect the strength of the relationships between alcohol-related SNS use and alcohol consumption as well. This can be explained using insights from theories such as Bushman's $(1995,1996)$ extension of Berkowitz' (1984) cognitive neo-association model and Lang's (2006) limited capacity model of mediated message processing (LC4MP). These models postulate that the human ability to process information is limited, and dependent on a combination of message aspects and individual differences (Lang, 2006). In order to understand this interaction, one should know that the human memory is a collection of networks, consisting of units or nodes (Anderson and Bower, 1973; Berkowitz, 1984; Bushman, 1995, 1996; Lang, 2006). A node can be understood as a representation of a mental concept, thought, feeling or belief, and is connected with other nodes via associative pathways. When information from a message is processed, and a node is activated, that activation spreads throughout the associative network of nodes, priming related thoughts and feelings (Anderson and Bower, 1973; Berkowitz, 1984). The extent to which information is processed is dependent on interactions between message aspects and human motivational processes (Lang, 2006).

One such human motivational process stems from an individual's personality. Personality traits can increase the centrality, complexity and density of trait-related cognitive networks in an individual's minds. The more central, complex and/or dense a cognitive network, the easier related information is processed. Consequently, when individuals encounter (media) messages that are consistent with their personality traits (disposition-content congruency; Valkenburg \& Peter, 2013), this congruent content is expected to be processed faster and more effectively, spreading more easily throughout their existing mental network, potentially resulting in stronger media effects (Bushman, 1995, 1996; Lang, 2006). Moreover, when media content is congruent with an individual's dispositions, this can elicit an arousal response, increasing the automatic allocation of resources to processing the information and thus enhancing the media 
BIG FIVE IN ALCOHOL-RELATED SOCIAL MEDIA EFFECTS

effect (Lang, 2006). In contrast, when the media content is dispositionaly incongruent with an individual's personality traits, this can activate an aversive reaction resulting in an allocation of resources to protective strategies, thus potentially diminishing the strength of media effects (Lang, 2006).

Hence, we argue that adolescents with low conscientiousness, high neuroticism, low agreeableness, high extraversion or high openness for experience, may allocate more cognitive resources to the processing of alcohol-related SNS content because they are predisposed to be more attracted to alcohol cues. Consequently, we expect the associations between exposure to alcohol references and drinking behavior (H1) as well as between self-sharing these references and drinking behavior $(\mathrm{H} 2)$ to be strongest for these adolescents. These hypotheses will be tested while controlling for age, gender, age of onset, parental education and perceived parental permissibility of alcohol consumption, because each of these variables has been shown to be important predictors of adolescent drinking behavior (Melis et al., 2016).

\section{Method}

\section{Sample}

The study was part of a larger study on adolescents' lifestyles (XXXreference) ${ }^{1}$. Respondents were recruited in 16 secondary schools in Belgium, and adolescents in the $3^{\text {rd }}$ and $4^{\text {th }}$ year of the selected schools completed a paper-and-pencil survey after obtaining informed consent from a legal guardian. The school principal decided which classes could participate in the study. Secondary schools in Belgium consist of 6 years, and students typically start around the age of 12 in year 1, and finish around the age of 18 in year 6 . The schools were selected at random from the list of secondary schools in Belgium, and are representative of the schools in the country as schools from all educational systems are represented. In particular, $18 \%$ of the

\footnotetext{
${ }^{1}$ The study by XXXreference used the same dataset, but examined whether the behavioral activation system (BAS) and behavioral inhibition system (BIS) can moderate the relation between soap opera viewing and alcohol attitudes. Hence, although the same dataset is used, the analyses presented in this manuscript have not been published before.
} 
BIG FIVE IN ALCOHOL-RELATED SOCIAL MEDIA EFFECTS

respondents were enrolled in vocational education (e.g., hairdresser, welder), $13 \%$ were enrolled in technical education (e.g., social and technical sciences, tourism), 3\% were enrolled in arts education (e.g., interior architect, drama), and 66\% were enrolled in general education (e.g., mathematics, languages).

Confidentiality was assured before and after the completion of the questionnaire (both written and oral) and respondents were informed that they could cease their participation at any time without justification. A researcher remained present during the data collection to answer any potential questions. No incentive was given. Despite the fact that the study adheres to all possible ethical and legal guidelines, no official IRB approval was obtained. In Belgium, research can only be reviewed for ethical approval by the research institution itself, as commercial review boards do not exist. However, according to the Belgian law, only research related to health science practices or including medical or pharmacological procedures needs ethical approval. As a result, the university's ethical committee for research on human subjects that does not fall under the scope of this law, was not founded until April 1, 2014, when more than $55 \%$ of our data had already been collected. Before the foundation of our IRB, research in the social sciences - including this work - was permitted to be done without IRB approval, as there was no review board for non-medical research in existence.

Data were collected among a sample of 922 mid-adolescents. Six percent of this sample $(n=52)$ was younger than 14 , older than 16 , or did not share their age, and were subsequently deleted from the sample. So, 866 respondents between the ages of 14 and 16 remained $\left(\mathrm{M}_{\text {subsample }}=14.85, \mathrm{SD}=.71,57.5 \%\right.$ girls $)$. Roughly half of participants indicated that their parents had received tertiary education (53.6\% mothers, $46 \%$ fathers) and one out of five indicated that their parents had received secondary education (19\% mothers, $22.4 \%$ fathers). About 5\% indicated that their parents had received no education (3.8\% mothers, $5.1 \%$ fathers), and about one fourth of the respondents did not know the education level of their parents 
BIG FIVE IN ALCOHOL-RELATED SOCIAL MEDIA EFFECTS

(23.7\% mothers, $26.4 \%$ fathers). School results of the pupils followed a normal distribution around a mean of $70 \%(\mathrm{M}=69.84, \mathrm{SD}=8.44$; skewness= -.36).

\section{Measures}

Exposure to alcohol references on SNS was measured by asking respondents how often they see videos or images (1) on YouTube or similar sites or (2) on other SNS, such as Facebook or Twitter, about (a) youth drinking alcohol and (b) youth being drunk. Answers ranged from (0) never to (8) all day long. Factor analysis indicated that the four items loaded onto one scale with good internal reliability (Eigenvalue=3.05, Explained variance=76.12, $\alpha=.89)$.

Sharing alcohol references on SNS was measured using a similar scale and response options as exposure to alcohol references on SNS, but respondents were asked how often they shared this content themselves (Eigenvalue $=3.47$, explained variance $=86.64, \alpha=.95$ ). Considering that very few adolescents this age shared alcohol references more than a few times per month $(n=13)$, the upper scale points were collapsed after calculating the composite score with (0) never, (1) a few times per year, (2) once per month, and (3) more than once per month.

FFM was measured with the previously demonstrated reliable and valid 44-item Big Five Inventory (John and Srivastava, 1999). Answers ranged from (1) not at all like me to (5) very much like me. The extraversion subscale has 8 items (e.g., 'I see myself as someone who is talkative'). The agreeableness subscale has 9 items (e.g., 'considerate and kind to almost everyone'). The conscientiousness subscale has 9 items (e.g., 'does things efficiently'). The neuroticism subscale has 8 items (e.g., 'tense'), and the openness to experience subscale has 10 items (e.g., 'curious about many different things'). Factor analysis indicated that agreeableness did not sufficiently load onto one factor and the agreeableness items were scattered across the other four factors. When deleting agreeableness, four unique factors could be extracted as predicted by the Big Five Inventory. However, the items 'depressed, blue' and 
BIG FIVE IN ALCOHOL-RELATED SOCIAL MEDIA EFFECTS

'moody' had to be deleted from the neuroticism subscale and 'prefers work that is routine' had to be deleted from the openness subscale. Such items were deleted because their factor loadings were below .40 (Field, 2009). Eigenvalues indicated that after deletion of these items, the four factors explained $15.71 \% \quad$ (eigenvalue $=4.87$ ), $11.89 \% \quad$ (eigenvalue $=3.69), \quad 8.96 \%$ (eigenvalue $=2.78$ ) and $7.88 \%$ (eigenvalue $=2.44$ ) of the variance. Reliability analyses confirmed that agreeableness was not a very reliable subscale $(\alpha=.63)$, and that the previously mentioned three items should be dropped from the neuroticism and openness subscales $\left(\alpha_{\text {neuroticism items deleted }}=.79, \alpha_{\text {openness items deleted }}=.75, \alpha_{\text {extraversion }}=.81, \alpha_{\text {conscientiousness }}=.74\right)$. Hence, only neuroticism, openness, extraversion and conscientiousness were further analyzed.

Alcohol consumption was measured by multiplying the frequency of alcohol consumption ((0) never to (4) 4 times per week or more) with the amount of alcohol consumed on a typical day of drinking ((0) nothing to (5) 10 glasses or more), which is a widely used instrument to measure alcohol consumption (Rehm, 1998; Sobell and Sobell, 2004).

There were 5 control variables added. The first two control variables were gender $\left({ }^{\prime} 0\right.$ ' $=$ male, ' 1 '=female) and age (open question). The third control variable was age of onset, (open question 'How old were you when you consumed alcohol for the first time?' with 'not drinking yet' recoded as age 17, as this would reflect future behavior among 14-16-year-olds). Parental education was used as a proxy for SES. Respondents were asked to indicate their mother's and father's highest level of education. Because more than $25 \%$ did not know their parents' education level, parental education was dummy-coded as 'unknown education', 'secondary education' and 'tertiary education' using 'primary school education' as the reference category for both parents separately. Finally, perceived parental permissibility of alcohol consumption was added for both parents separately, with (0) absolute disapproval and (6) absolute approval. 
BIG FIVE IN ALCOHOL-RELATED SOCIAL MEDIA EFFECTS

\section{Analyses}

SPSS 24 was used for all analyses. First, descriptive statistics and bootstrapped (1000 samples) correlation analyses were calculated. Bootstrapped polynomial regression with response surface modeling was then used to test the interaction between FFM personality traits and alcohol-related SNS use. This technique provides more nuanced results than traditional moderated regression as it simultaneously analyzes non-linear as well as linear interactions in a three-dimensional way (Shanock et al., 2010).

To test the interactions, three new variables were created for each analysis (Edwards, 2002; Shanock et al., 2010): (a) the square of the standardized alcohol-related SNS variable (sharing or exposure), the square of the standardized FFM variable, and (c) the cross-product of the standardized SNS variable and the standardized FFM scales (computed for each FFM variable separately). All variables except gender and the dummy variables were standardized as Zscores $(M=0, S D=1)$. Next, the polynomial regression was run by regressing the outcome variable (alcohol consumption) on the standardized control variables (block 1), the standardized SNS and FFM variables (block 2), and the newly created squared and crossproduct variables (block 3) (Edwards, 2002; Shanock et al., 2010). One analysis was run per interaction, with block 1 and 2 containing the same variables in all analyses, and the variables in block 3 dependent on the interaction being tested. In polynomial regression, whether or not the variance in the outcome explained by block $3\left(\Delta R^{2}\right)$ is different from zero is examined; in which case there is a significant interaction. Four surface test values are then evaluated in order to interpret the direction, strength, and linearity of the interaction $\left(a_{1}, a_{2}, a_{3}, a_{4}\right)$ (Shanock et al., 2010 for an extensive overview). Once the four surface values have been calculated, a threedimensional response surface is graphed in Excel to aid interpretation (Edwards, 2002; Shanock et al., 2010). Multicollinearity was not found to be a problem (Field, 2009). 
BIG FIVE IN ALCOHOL-RELATED SOCIAL MEDIA EFFECTS

\section{Results}

\section{Descriptive Results}

Half of the adolescents in our sample indicated that they had consumed alcohol (52.3\%) with an average age of onset at age 13 ( $\mathrm{M}_{\text {drinkers only }}=13.10, \mathrm{SD}=1.68 ; \mathrm{M}_{\text {corrected }}$ for nondrinkers=14.71, $\mathrm{SD}=2.31)$. On average, adolescents consumed alcohol less than once per month and consumed two or three glasses of alcohol on a typical drinking day. Only $11.3 \%(n=97)$ of the adolescents in our sample indicated they shared alcohol references on SNS, but $84.4 \%$ $(n=724)$ indicated they had been exposed to the alcohol references of others. On average, adolescents shared these references less than once a year and were exposed to them about once every two months (see Table 1). One out of every four adolescents who shared alcohol references, reported not having consumed alcohol before.

TABLE 1 ABOUT HERE

\section{Hypothesis Testing}

Before examining the hypothesized interactions, the direct associations between alcoholrelated SNS use, FFM, and alcohol consumption were analyzed based on block 1 and 2 of the polynomial regression (see Table 2). The results indicated that more frequent exposure to online alcohol references of peers was directly related to more alcohol consumption: Those who were more frequently exposed to alcohol references on social media also reported the highest amounts of alcohol consumption. Additionally, scoring low on conscientiousness or high on extraversion were directly associated with higher levels of alcohol consumption. Contrary to our expectations, sharing alcohol references on SNS, openness to experience, and neuroticism had very low effect sizes and were not significantly associated with drinking behavior. However, additional testing indicated that the relationship between self-sharing and alcohol consumption was non-linear and concave $\left(R^{2}\right.$ change $=.01, p<.001, b(S E)_{1}=1.01(.40)$, 
BIG FIVE IN ALCOHOL-RELATED SOCIAL MEDIA EFFECTS

$\left.\beta_{1}=.30, t_{1}=3.35, p_{1}<.05, b(S E)_{2}=-.18(.07), \beta_{2}=-.29, t_{2}=-3.21, p_{2}<.01\right)$. No other direct non-linear relationships were detected.

\section{TABLE 2 ABOUT HERE}

Next, the non-significant $\Delta \mathrm{R}^{2}$ 's of block 3 indicated that none of the personality traits moderated the exposure pathway, thus refuting hypothesis 1 (See Table 3). Hypothesis 2 predicted that especially adolescents with low conscientiousness, high neuroticism, high extraversion, or high openness for experience would consume more alcohol when sharing alcohol references. In support of this hypothesis, we found that all personality traits moderated the sharing pathway.

\section{TABLE 3 ABOUT HERE}

More specifically, we found that there was a significant positive linear interaction across the agreement line ${ }^{2}\left(\mathrm{a}_{1}\right)$ of sharing and extraversion, of sharing and neuroticism, and of sharing and openness. This means that, as expected, alcohol consumption increases as both sharing and extraversion/neuroticism/openness increase to the same degree, whereby those who rarely share alcohol references and have low extraversion/neuroticism/openness have the lowest alcohol consumption, and those who frequently share alcohol references and have high extraversion/neuroticism/openness have the highest alcohol consumption. Moreover, in line with our expectations, we did not find a significant linear agreement interaction between selfsharing and conscientiousness $\left(\mathrm{a}_{1}\right)$.Those with low conscientiousness who do not share alcohol references do not consume less alcohol compared to those with high conscientiousness who frequently share alcohol references.

\section{FIGURE 1 ABOUT HERE}

\footnotetext{
${ }^{2}$ The agreement line is the line at which $\mathrm{X}$ (self-sharing) $=\mathrm{Y}$ (personality). Thereby, $\mathrm{X}=\mathrm{Y}=0$ represents the average respondent, $\mathrm{X}=\mathrm{Y}=-1$ represents respondents who score $1 \mathrm{SD}$ below the mean for both $\mathrm{X}$ and $\mathrm{Y}$, and $\mathrm{X}$ $=\mathrm{Y}=1$ represents respondents who scare $1 \mathrm{SD}$ above the mean for both $\mathrm{X}$ and $\mathrm{Y}$ (For more detailed information see Edwards and Parry, 1993; Shanock et al., 2010).
} 
BIG FIVE IN ALCOHOL-RELATED SOCIAL MEDIA EFFECTS

Closer inspection of the slopes across the line of discrepancy ${ }^{3}\left(a_{3}\right)$ indicates that for conscientiousness, openness and neuroticism - but not for extraversion - alcohol consumption is higher for those frequently sharing alcohol references with low-level personality traits, compared to those with high levels of conscientiousness, openness, or neuroticism who never share alcohol references. Furthermore, the curvature of the line of discrepancy (a4) is concave for openness, but not for conscientiousness, neuroticism nor extraversion. This means that the slope of alcohol consumption is steeper for those who rarely share alcohol references and who also have high levels of openness, than for those who frequently share alcohol references and have low levels of openness, whereby alcohol consumption levels out for those frequently sharing with low levels of openness. See Figure 1 for all response surfaces.

\section{Discussion}

SNS have created an environment in which users are continually exposed to peer behaviors and opinions, while simultaneously being encouraged to express themselves (Moreno, Kota, et al., 2013). This has resulted in new areas of media effects research; moving away from traditional mass exposure towards peer exposure and self-sharing effects research (Moreno, Kota, et al., 2013; Valkenburg, 2017). The present study advances the knowledge on healthrelated SNS effects by assessing the conditionality of the associations between both selfsharing of and exposure to peers' online alcohol references and drinking behavior among midadolescents on the threshold of the legal drinking age.

First, the finding that more frequent exposure to peers' alcohol-related content is related to more alcohol consumption, is consistent with the proposition that health-related behaviors are socially learned (Bandura, 1971, 2009; Oetting and Donnermeyer, 1998), and that SNS can be vectors of peer influence (Moreno, Kota, et al., 2013). However, the disposition-content

\footnotetext{
${ }^{3}$ The line of discrepancy is the line at which $X$ (self-sharing) $=-Y$ (personality). Again, $X=-Y=0$ represents the average respondent. In contrast, $\mathrm{X}=-\mathrm{Y}=1$ represents respondents who score 1SD below the mean for $\mathrm{Y}$ and 1SD above the mean for $\mathrm{X}$, and $\mathrm{X}=-\mathrm{Y}=-1$ represents respondents who score $1 \mathrm{SD}$ above the mean for $\mathrm{Y}$ and 1 SD below the mean for X (For more detailed information see Edwards and Parry, 1993; Shanock et al., 2010).
} 
BIG FIVE IN ALCOHOL-RELATED SOCIAL MEDIA EFFECTS

congruency hypothesis was not confirmed. Regardless of their dispositional vulnerability, exposure to peer content was similarly associated with alcohol consumption for all adolescents. This may potentially be explained by adolescents' strong focus on peers and their intense desire to fit in (Steinberg, 2008). In general, adolescents hold positive attitudes towards alcohol and the most important reason to consume alcohol is to have fun with friends (Melis et al., 2016). Consequently, adolescents' appetitive system may automatically be triggered when they are exposed to peers' alcohol references; simply because the references stem from their peers. Potentially, it is only when they grow older and less reactive to peer cues, that their personality activates differential processing mechanisms (Steinberg, 2008). This would be in line with a prior finding that only older adolescents indicate that their 'strong personality' is a decisive factor in abstaining from alcohol (Melis et al., 2016).

In contrast to our expectations, we found no direct linear relationship between sharing alcohol references and alcohol consumption. However, additional probing indicated that for adolescents of this age, this association was concave in that sharing alcohol references is related to greater alcohol consumption, regardless of how often they share. This may be because only $10 \%$ of our sample was sharing alcohol references, and of those who did share alcohol references, $25 \%$ did not consume alcohol. In contrast, studies with older adolescents (over the legal drinking age) find linear associations between sharing and alcohol consumption, potentially because more than $70 \%$ of their respondents report sharing alcohol references (Geusens and Beullens, 2018). This disparity indicates that alcohol references on SNS may hold different meanings for adolescents under or on the verge of the legal drinking age compared to older adolescents and emerging adults. Hence, our results clearly demonstrate the need for more qualitative research to unravel the differential meaning of online alcohol references shared by younger versus older individuals. One difference in meaning that should be tested is the proposition that alcohol references shared by older adolescents and emerging 
BIG FIVE IN ALCOHOL-RELATED SOCIAL MEDIA EFFECTS

adults may reflect memories of fun drinking events with friends (Hebden et al., 2015; Hendriks et al., 2017; Niland et al., 2014). Yet for younger adolescents, they might reflect attempts to fit in with drinking and sharing peers, or to try out possible drinking selves before actually engaging in alcohol consumption (Moreno et al., 2009). This hypothesis would be in line with our finding that one out of four adolescents in our sample shared alcohol references without consuming alcohol, and when testing a reverse model we found neither a linear nor a non-linear association between alcohol consumption and self-sharing.

Third, the present study is the first to examine the moderating role of personality in riskrelated social media effects and to demonstrate the disposition-content congruency hypothesis (Valkenburg and Peter, 2013) for SNS self-effects. Specifically, we found that high extraversion, neuroticism, or openness, and low conscientiousness each strengthened the association between self-sharing and alcohol consumption. Moreover, considering that openness and neuroticism were not directly associated with alcohol consumption, and selfsharing was only non-linearly related to alcohol consumption, this demonstrates that when researching middle adolescents' drinking behavior, it is crucial to study combinations of factors. Thus, based on our findings, it appears that the combination of specific internal personality traits and external factors (i.e. self-sharing alcohol references on SNS), may potentially trigger an individual's dispositional vulnerability to alcohol cues, resulting in more elaborate processing of their self-shared content. Thereby, it should be noted that no significant associations were found between self-sharing and any of the personality traits, which means that dispositionaly vulnerable adolescents are not simply more likely to experience this interaction because they self-share alcohol references more often.

Finally, no evidence was found for the disposition-content incongruency hypothesis. Following Lang (2006), we expected an aversive reaction when sharing alcohol references was not in line with the predisposition. However, those who shared alcohol references but had low- 
BIG FIVE IN ALCOHOL-RELATED SOCIAL MEDIA EFFECTS

risk personality traits were not drinking any less than more average respondents. Thus, while personality seems to reinforce the association between sharing alcohol references and alcohol consumption for alcohol-predisposed adolescents, it does not diminish the association for adolescents who are dispositionaly low-risk. This demonstrates the importance of alcoholrelated sharing behavior in young individuals' drinking behavior: If adolescents share alcohol references on SNS, they are more likely to engage in heavier drinking behavior, even if they would have been dispositionaly less likely to drink if they had not engaged in alcohol-related social media use.

\section{Limitations}

While the present study has advanced the understanding of adolescents' health-risk-related SNS effects, several limitations should be acknowledged. First, the study relied on self-reports, though it has been shown that self-report measures on alcohol use are usually reliable (Simons et al., 2015). Second, our cross-sectional data do not allow us to infer causation and adolescents who consume more alcohol are likely the ones sharing the most alcohol references so could potentially also seek out peers with similar sharing and drinking habits. In fact, prior longitudinal research has shown that the association between alcohol-related SNS use and drinking behavior is reciprocal (Geusens and Beullens, 2017a). Hence, even if SNS use does not predict alcohol consumption, but merely reflects it, the results of this study remain relevant as they help to identify a group of adolescent drinkers. Third, the study was conducted in Belgium, a country with a fairly accepting alcohol culture and low ethnic diversity. Consequently, the results of this study may not be generalizable across other populations and more research is needed to understand how cultural differences can affect the studied associations. Nevertheless, a very recent cross-cultural study comparing alcohol-related social media effects among Belgian and US college students, found the associations between alcohol- 
BIG FIVE IN ALCOHOL-RELATED SOCIAL MEDIA EFFECTS

related social media use and drinking behavior to be very similar in both populations (Geusens et al., 2019).

Fourth, not all FFM subscales fitted equally well for our sample. Specifically, agreeableness had to be dropped entirely because the items would not load onto one scale and distorted the factor loadings of the other scales. Finally, LC4MP (Lang, 2006) and the cognitive neoassociation model (Berkowitz, 1984; Bushman, 1995, 1996) were used as theoretical frameworks for our study and findings. However, the study was not set up to test these models as the actual processing of the SNS content was not measured. Experimental studies could elaborate on whether differential processing is indeed a good explanation for our differential susceptibility findings.

\section{Implications and Contribution}

The present study is the first to examine the dispositional conditionality of the self-sharing and exposure pathways of alcohol-related SNS use among adolescents on the threshold of legal alcohol consumption. We thereby showed that alcohol-related SNS use can be related to adolescent alcohol consumption in several ways. First, sharing alcohol references relates to more alcohol consumption, regardless of how often the alcohol references are shared. Second, adolescents who are dispositionaly predisposed are especially vulnerable to this relation. Third, when peers are exposed to these alcohol references more often, they too consume more alcohol, regardless of their personality traits. This demonstrates that we should be aware of the role SNS play in the drinking behavior of adolescents on the verge of legal drinking. Drinking prevention interventions including media literacy (e.g., Greene, 2013) could potentially be useful to not only reduce alcohol consumption among this age group, but also diminish the role social media play in adolescents' drinking behavior. 
BIG FIVE IN ALCOHOL-RELATED SOCIAL MEDIA EFFECTS

\section{References}

Anderson, J., and Bower, G. (1973). Human associative memory. Washington, DC: V. H. Winston.

Bandura, A. (1971). Social learning theory. New York, NY: General Learning Press.

Bandura, A. (2009). Social cognitive theory of mass communication. In J. Bryant and M. B. Oliver (Eds.), Media effects: Advances in theory and research (3rd ed., pp. 94-124). New York, NY: Routledge.

Berkowitz, L. (1984). Some effects of thoughts on anti- and prosocial influences of media events: A cognitive-neoassociation analysis. Psychological Bulletin, 95(3), 410-427. doi: 10.1037/0033-2909.95.3.410

Beullens, K., and Schepers, A. (2013). Display of alcohol use on Facebook: A content analysis. Cyberpsychology, behavior and social networking, 16(7), 497-503. doi: 10.1089/cyber.2013.0044

Beullens, K., and Vandenbosch, L. (2016). A conditional process analysis on the relationship between the use of social networking sites, attitudes, peer norms and adolescents' intentions to consume alcohol. Media Psychology, 19(2), 310-333. doi: $10.1080 / 15213269.2015 .1049275$

Bushman, B. J. (1995). Moderating role of trait aggressiveness in the effects of violent media on aggression. Journal of Personality and Social Psychology, 69, 950-960. doi: $10.1037 / / 0022-3514.69 .5 .950$

Bushman, B. J. (1996). Individual differences in the extent and development of aggressive cognitive-associative networks. Personality and Social Psychology Bulletin, 22, 811819. doi: $10.1177 / 0146167296228004$

Costa, P. T., and McCrae, R. (1992). Revised NEO personality inventory (NEO-PI-R) and NEO five-factor inventory (NEO-FFI) professional manual. Odessa, FL: Psychological 
BIG FIVE IN ALCOHOL-RELATED SOCIAL MEDIA EFFECTS

Assessment Resources.

D’Angelo, J., Kerr, B., and Moreno, M. a. (2014). Facebook displays as predictors of binge drinking: From the virtual to the visceral. Bulletin of Science, Technology \& Society, 34, 159-169. doi: 10.1177/0270467615584044

Edwards, J. R. (2002). Alternatives to difference scores: Polynomial regression analysis and response surface methodology. In F. Drasgow and N. Schmitt (Eds.), Measuring and analyzing behavior in organizations: Advances in measurement and data analysis (pp. 351-400). San Francisco, CA: Jossey-Bass. doi: 10.1037/e576892011-020

Edwards, J. R., and Parry, M. E. (1993). On the use of polynomial regression equations as an alternative to difference scores in organizational research. Academy of Management Journal, 36(6), 1577-1613.

Field, A. (2009). Discovering statistics using SPSS (3rd ed.). Thousand Oaks, CA: Sage.

Geusens, F., and Beullens, K. (2017a). The reciprocal associations between sharing alcohol references on social networking sites and binge drinking: A longitudinal study among late adolescents. Computers in Human Behavior, 73, 499-506. doi: 10.1016/j.chb.2017.03.062

Geusens, F., and Beullens, K. (2017b). Strategic self-presentation or authentic communication? Predicting adolescents' alcohol references on social media. Journal of Studies on Alcohol and Drugs, 78, 124-133. doi: 10.15288/jsad.2017.78.124

Geusens, F., and Beullens, K. (2018). The association between social networking sites and alcohol abuse among Belgian adolescents: The role of attitudes and social norms. Journal of Media Psychology, 30, 207-216. doi: 10.1027/1864-1105/a000196

Geusens, F., and Beullens, K. (2019). A longitudinal examination of the moderating influence of peer and parental socialization on alcohol-related social media self-effects among late adolescents. Media Psychology, 22, 273-297. Routledge. doi: 
BIG FIVE IN ALCOHOL-RELATED SOCIAL MEDIA EFFECTS

$10.1080 / 15213269.2018 .1476159$

Geusens, F., Bigman-Galimore, C. A., and Beullens, K. (2019). A cross-cultural comparison of the processes underlying the associations between sharing of and exposure to alcohol references and drinking intentions. New Media \& Society, online fir. doi:

$10.1177 / 1461444819860057$

Graziano, W. G., and Tobin, R. M. (2016). Agreeableness and the five factor model. In T. A. Widiger (Ed.), The Oxford Handbook of the Five Factor Model. Oxford University Press. doi: 10.1093/oxfordhb/9780199352487.013.17

Greene, K. (2013). The theory of active involvement: Processes underlying interventions that engage adolescents in message planning and/or production. Health Communication, 28(7), 644-656. doi: 10.1080/10410236.2012.762824

Hebden, R., Lyons, A. C., Goodwin, I., and McCreanor, T. (2015). "When you add alcohol, it gets that much better": University students, alcohol consumption, and online drinking cultures. Journal of Drug Issues, 45(2), 214-226. doi: 10.1177/0022042615575375

Hendriks, H., Gebhardt, W. A., and van den Putte, B. (2017). Alcohol-related posts from young people on social networking sites: Content and motivations. Cyberpsychology, Behavior, and Social Networking, 20, 428-435. doi: 10.1089/cyber.2016.0640

Hong, R. Y., and Paunonen, S. V. (2009a). Personality traits and health-risk behaviours in university students. European Journal of Personality, 23(8), 675-696. doi: 10.1002/per.736

Hong, R. Y., and Paunonen, S. V. (2009b). Personality traits and health-risk behaviours in university students. European Journal of Personality, 23(8), 675-696. doi: 10.1002/per.736

Ibáñez, M. I., Moya, J., Villa, H., Mezquita, L., Ruipérez, M. Á., and Ortet, G. (2010). Basic personality dimensions and alcohol consumption in young adults. Personality and 
BIG FIVE IN ALCOHOL-RELATED SOCIAL MEDIA EFFECTS

Individual Differences, 48(2), 171-176. Elsevier Ltd. doi: 10.1016/j.paid.2009.09.017

Jackson, J. J., and Roberts, B. W. (2015). Conscientiousness. In T. A. Widiger (Ed.), The

Oxford Handbook of the Five Factor Model. Oxford University Press. doi:

10.1093/oxfordhb/9780199352487.013.18

John, O. P., and Srivastava, S. (1999). The Big-Five trait taxonomy: History, measurement and theoretical perspectives. In L. A. Perven and O. P. John (Eds.), Handbook of personality: Theory and research (Vol. 2, pp. 102-138). New York, NY: Guilford Press. doi: $10.1525 /$ fq.1998.51.4.04a00260

Krcmar, M. (2009). Individual differences in media effects. In R. L. Nabi and M. B. Oliver (Eds.), The SAGE Handbook of Media Processes and Effects (pp. 237-250). Thousand Oaks, CA: Sage.

Lang, A. (2006). Using the limited capacity model of motivated mediated message processing to design effective cancer communication messages. Journal of Communication, 56(SUPPL.), 57-80. doi: 10.1111/j.1460-2466.2006.00283.x

Litt, D. M., and Stock, M. L. (2011). Adolescent alcohol-related risk cognitions: The roles of social norms and social networking sites. Psychology of Addictive Behaviors, 25(4), 708-713. doi: 10.1037/a0024226

Malouff, J. M., Thorsteinsson, E. B., Rooke, S. E., and Schutte, N. S. (2007). Alcohol involvement and the five-factor model of personality: A meta-analysis. Journal of Drug Education, 37(3), 277-294. doi: 10.2190/DE.37.3.d

Melis, S., Rosiers, J., De Paepe, N., and Geirnaert, M. (2016). VAD-leerlingenbevraging in het kader van een drugbeleid op school. doi: D/2010/6030/15

Mellos, E., Ioannis, L., and Paparrigopoulos, T. (2010). Comorbidity of personality disorders with alcohol abuse. In Vivo, 24(5), 761-770. doi: 24/5/761 [pii]

Moreno, M. A., Briner, L. R., Williams, A., Brockman, L., Walker, L., and Christakis, D. a. 
BIG FIVE IN ALCOHOL-RELATED SOCIAL MEDIA EFFECTS

(2010). A content analysis of displayed alcohol references on a social networking web site. Journal of Adolescent Health, 47(2), 168-175. Elsevier Ltd. doi:

10.1016/j.jadohealth.2010.01.001

Moreno, M. A., Briner, L. R., Williams, A., Walker, L., and Christakis, D. a. (2009). Real use or "real cool": Adolescents speak out about displayed alcohol references on social networking websites. Journal of Adolescent Health, 45(4), 420-422. Elsevier Ltd. doi: 10.1016/j.jadohealth.2009.04.015

Moreno, M. A., Kacvinsky, L., Pumper, M., Wachowski, L., and Whitehill, J. M. (2013). Associations between social media displays and event-specific alcohol consumption by college students. Wisconsin Medical Journal, 112(6), 251-256.

Moreno, M. A., Kota, R., Schoohs, S., and Whitehill, J. M. (2013). The Facebook influence model: A concept mapping approach. Cyberpsychology, behavior and social networking, 16(7), 504-11. doi: 10.1089/cyber.2013.0025

Niland, P., Lyons, A. C., Goodwin, I., and Hutton, F. (2014). "See it doesn't look pretty does it?" Young adults' airbrushed drinking practices on Facebook. Psychology \& health, 29(8), 877-95. doi: 10.1080/08870446.2014.893345

Oetting, E. R., and Donnermeyer, J. F. (1998). Primary Socialization Theory, the etiology of drug use and deviance. I. Substance Use \& Misuse, 33(4), 995-1026. doi: $10.3109 / 10826089809056252$

Oliver, M. B., and Krakowiak, K. M. (2009). Individual differenecs in media effects. In J. Bryant and M. B. Oliver (Eds.), Media effects: Advances in theory and research (3rd ed., pp. 517-531). New York, NY: Routledge.

Rehm, J. (1998). Measuring quantity, frequency, and volume of drinking. Alcoholism: Clinical and Experimental Research, 22(supplement 2), 4s-14s. doi: 10.1111/j.15300277.1998.tb04368.x 
BIG FIVE IN ALCOHOL-RELATED SOCIAL MEDIA EFFECTS

Shanock, L. R., Baran, B. E., Gentry, W. A., Pattison, S. C., and Heggestad, E. D. (2010). Polynomial regression with response surface analysis: A powerful approach for examining moderation and overcoming limitations of difference scores. Journal of Business and Psychology, 25(4), 543-554. doi: 10.1007/s10869-010-9183-4

Simons, J. S., Wills, T. A., Emery, N. N., and Marks, R. M. (2015). Quantifying alcohol consumption: Self-report, transdermal assessment, and prediction of dependence symptoms. Addictive Behaviors, 50, 205-212. Elsevier Ltd. doi:

10.1016/j.addbeh.2015.06.042

Skewes, M. C., and Gonzalez, V. M. (2013). The biopsychosocial model of addiction. In P. M. Miller (Ed.), Principles of Addiction: Comprehensive Addictive Behaviors and Disorders, Volume 1 (pp. 61-70). San Diego, CA: Elsevier Academic Press. doi: 10.1016/B978-0-12-398336-7.00006-1

Slater, M. D. (2007). Reinforcing spirals: The mutual influence of media selectivity and media effects and their impact on individual behavior and social identity. Communication Theory, 17(3), 281-303. doi: 10.1111/j.1468-2885.2007.00296.x

Slater, M. D., Henry, K. L., Swaim, R. C., and Anderson, L. L. (2003). Violent media content and aggressiveness in adolescents: A downward spiral model. Communication Research, 30(6), 713-736. doi: 10.1177/0093650203258281

Sobell, L. C., and Sobell, M. B. (2004). Alcohol Consumption Measures. Assessing Alcohol Problems: A Guide for Clinicians and Researchers, 75-100. doi: 10.1007/978-1-46120357-5

Steinberg, L. (2008). A social neuroscience perspective on adolescent risk-taking. Developmental Review, 28(1), 78-106. doi: 10.1016/j.dr.2007.08.002

Sutin, A. R. (2015). Openness. In T. A. Widiger (Ed.), The Oxford Handbook of the Five Factor Model. Oxford University Press. doi: 10.1093/oxfordhb/9780199352487.013.16 
BIG FIVE IN ALCOHOL-RELATED SOCIAL MEDIA EFFECTS

Tackett, J. L., and Lahey, B. B. (2016). Neuroticism. In T. A. Widiger (Ed.), The Oxford Handbook of the Five Factor Model. Oxford University Press. doi: 10.1093/oxfordhb/9780199352487.013.14

Valkenburg, P. M. (2017). Understanding self-effects in social media. Human Communication Research, 43, 477-490. doi: 10.1111/hcre.12113

Valkenburg, P. M., and Peter, J. (2013). The differential susceptibility to media effects model. Journal of Communication, 63(2), 221-243. doi: 10.1111/jcom.12024

Vangeel, J., Beullens, K., Goossens, L., Vervoort, L., De Cock, N., Van Lippevelde, W., and Eggermont, S. (2016). A reinforcement sensitivity perspective on adolescents' susceptibility to the influence of soap opera viewing on alcohol attitudes. Mass Communication and Society, 19(4), 452-475. doi: 10.1080/15205436.2015.1111388

WHO. (2014). Global status report on alcohol and health. World Health Organization. Geneva, CH. Retrieved from http://www.who.int/substance_abuse/publications/global_alcohol_report/msbgsruprofile s.pdf

Widiger, T. A. (2016). Introduction. In T. A. Widiger (Ed.), The Oxford Handbook of the Five Factor Model. Oxford University Press. doi:

10.1093/oxfordhb/9780199352487.013.9

Wilt, J., and Revelle, W. (2016). Extraversion. In T. A. Widiger (Ed.), The Oxford Handbook of the Five Factor Model. Oxford University Press. doi:

10.1093/oxfordhb/9780199352487.013.15 


\section{BIG FIVE IN ALCOHOL-RELATED SOCIAL MEDIA EFFECTS}

Table 1. Results of the Bootstrapped (1000 samples) Correlation Analyses and Descriptives of the Main Constructs in the Analyses

\begin{tabular}{|c|c|c|c|c|c|c|c|c|c|c|c|c|c|c|c|c|c|}
\hline & 1. & 2. & 3. & 4. & 5. & 6. & 7. & 8. & 9. & 10. & 11. & 12. & 13. & 14. & 15. & 16. & 17. \\
\hline \multicolumn{18}{|l|}{$\begin{array}{l}\text { 1. Alcohol } \\
\text { consumption }\end{array}$} \\
\hline $\begin{array}{l}\text { 2. Exposure to peer } \\
\text { alcohol references }\end{array}$ & $.27 * * *$ & & & & & & & & & & & & & & & & \\
\hline $\begin{array}{l}\text { 3. Self-sharing of } \\
\text { alcohol references }\end{array}$ & .07 & $.33 * * *$ & & & & & & & & & & & & & & & \\
\hline 4. Conscientiousness & $-.16^{* * *}$ & $-.07 *$ & .04 & & & & & & & & & & & & & & \\
\hline 5. Openness & .02 & .04 & -.02 & $.10 * *$ & & & & & & & & & & & & & \\
\hline 6. Extraversion & $.16^{* * *}$ & $.14 * * *$ & .03 & .04 & $.21 * * *$ & & & & & & & & & & & & \\
\hline 7. Neuroticism & -.03 & -.06 & -.04 & .07 & -.03 & $-.22 * * *$ & & & & & & & & & & & \\
\hline 8. Age & $.25^{* * *}$ & $.16^{* * *}$ & .03 & .01 & .01 & -.04 & .06 & & & & & & & & & & \\
\hline 9. Age of onset & $-.51 * * *$ & $-.23 * * *$ & .01 & $.14 * * *$ & $-.09^{*}$ & $-.15^{* * *}$ & .03 & -.06 & & & & & & & & & \\
\hline $\begin{array}{l}\text { 10. Perceived } \\
\text { maternal } \\
\text { permissibility }\end{array}$ & $.33 * * *$ & $.15 * * *$ & -.01 & -.02 & -.002 & .04 & -.02 & $.17 * * *$ & $-.34 * * *$ & & & & & & & & \\
\hline $\begin{array}{l}\text { 11. Perceived } \\
\text { paternal } \\
\text { permissibility }\end{array}$ & $.32 * * *$ & $.16^{* * *}$ & -.01 & -.01 & .03 & .06 & -.02 & $.14 * * *$ & $-.34 * * *$ & $.80 * * *$ & & & & & & & \\
\hline $\begin{array}{l}\text { 13. Mother unknown } \\
\text { education }^{\text {a }}\end{array}$ & -.04 & -.03 & .06 & .02 & $-.13 * * *$ & -.01 & .03 & .01 & $.07 *$ & -.05 & $-.08^{*}$ & .02 & & & & & \\
\hline $\begin{array}{l}\text { 14. Mother } \\
\text { secondary education }{ }^{\mathrm{a}}\end{array}$ & -.04 & -.02 & -.04 & .06 & -.05 & $-.09^{*}$ & .06 & .04 & -.003 & .004 & .04 & .06 & $-.26 * * *$ & & & & \\
\hline $\begin{array}{l}\text { 15. Mother tertiary } \\
\text { education }{ }^{\text {a }}\end{array}$ & .04 & .04 & $-.09^{*}$ & -.05 & $.15^{* * *}$ & $.11^{* *}$ & $-.09^{*}$ & -.07 & -.06 & .04 & .04 & -.05 & $-.57 * * *$ & $-.50 * * *$ & & & \\
\hline $\begin{array}{l}\text { 16. Father unknown } \\
\text { education }^{\text {a }}\end{array}$ & -.06 & $-.07 *$ & .04 & .003 & $-.10 * *$ & -.05 & .02 & -.03 & .06 & -.06 & -.07 & .06 & $.69 * * *$ & $-.16^{* * *}$ & $-.41 * * *$ & & \\
\hline $\begin{array}{l}\text { 17. Father secondary } \\
\text { education }^{\mathrm{a}}\end{array}$ & $.09 *$ & .03 & -.02 & .03 & -.04 & -.06 & $.07 *$ & $.08^{*}$ & -.04 & $.10^{* * *}$ & $.10^{* *}$ & .02 & $-.20 * * *$ & $.36 * * *$ & -.07 & $-.31 * * *$ & \\
\hline $\begin{array}{l}\text { 18. Father tertiary } \\
\text { education }\end{array}$ & -.05 & -.003 & $-.10^{* *}$ & -.02 & $.16^{* * *}$ & $.12 * * *$ & $-.10 * *$ & $-.10 * *$ & -.03 & -.05 & -.06 & -.06 & $-.36^{* *}$ & $-.19 * * *$ & $.53 * * *$ & $-.52 * * *$ & $-.48 * * *$ \\
\hline M & 2.26 & 1.69 & .11 & 3.03 & 3.27 & 3.50 & 3.23 & 14.85 & 14.75 & 2.72 & 3.00 & & & & & & \\
\hline SD & 3.34 & 1.56 & .45 & .58 & .63 & .68 & .79 & .71 & 2.31 & 2.06 & 2.09 & & & & & & \\
\hline
\end{tabular}

Note: $* p<.05, * * p<.01, * * * p<.00 ; 1^{a}$ Parental education was dummy-coded using 'primary education level' as the reference category 
BIG FIVE IN ALCOHOL-RELATED SOCIAL MEDIA EFFECTS

Table 2

Results of the Traditional Bootstrapped (1000 samples) Linear Regression Analysis Predicting Alcohol Consumption

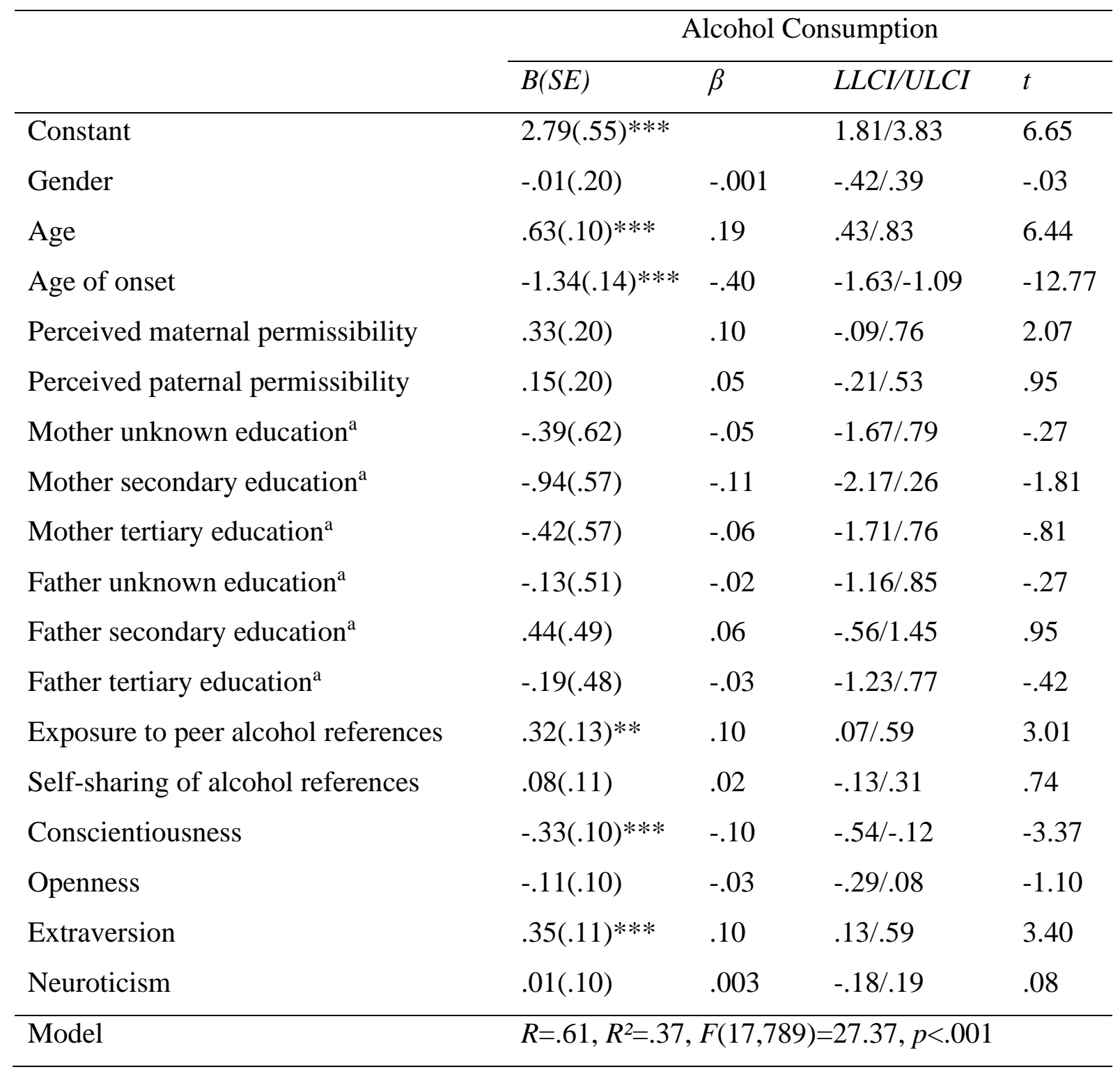

Notes: $* p<.05, * * p<.01, * * * p<.001 ;{ }^{a}$ Parental education was dummy-coded using 'primary education level' as the reference category 


\section{BIG FIVE IN ALCOHOL-RELATED SOCIAL MEDIA EFFECTS}

Table 3

Results of the Bootstrapped (1000 samples) Polynomial Regression and Response Surface Analyses of Alcohol Consumption on Alcohol-Related SNS Use and Personality

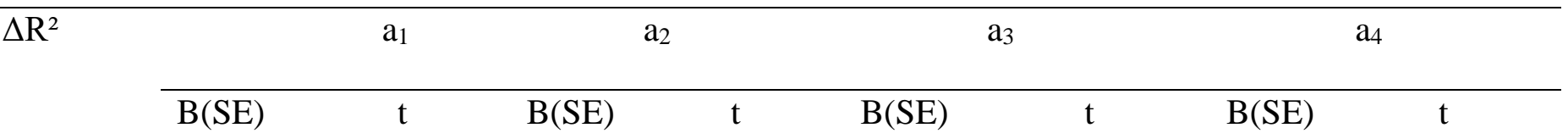

\begin{tabular}{|c|c|c|c|c|c|c|c|c|c|}
\hline Exposure x Conscientiousness & .002 & & & & & & & & \\
\hline Exposure x Openness & .001 & & & & & & & & \\
\hline Exposure $\mathrm{x}$ Extraversion & .003 & & & & & & & & \\
\hline Exposure x Neuroticism & .002 & & & & & & & & \\
\hline Sharing x Conscientiousness & $.01 * *$ & $.60(.40)$ & 1.50 & $-.23(.13)$ & -1.82 & $1.28(.40)^{* * *}$ & 3.21 & $.08(.15)$ & .53 \\
\hline Sharing x Openness & $.01 * *$ & $.85(.40) *$ & 2.10 & $-.18(.13)$ & -1.41 & $1.05(.40)^{* *}$ & 2.62 & $-.24(.12)^{*}$ & -2.00 \\
\hline Sharing $\mathrm{x}$ Extraversion & $.01^{* *}$ & $1.37(.41)^{* * *}$ & 3.33 & $-.09(.13)$ & -.69 & $.63(.42)$ & 1.50 & $-.03(.13)$ & -.25 \\
\hline Sharing x Neuroticism & $.01 * *$ & $.99(.41)^{*}$ & 2.42 & $-.11(.18)$ & -.61 & $.95(.40)^{*}$ & 2.36 & $-.20(.18)$ & -1.07 \\
\hline
\end{tabular}

Note: ${ }^{*} p<.05, * * p<.01, * * * p<.001 ;$ Response surface values not calculated if $\Delta R^{2}$ was not significant 

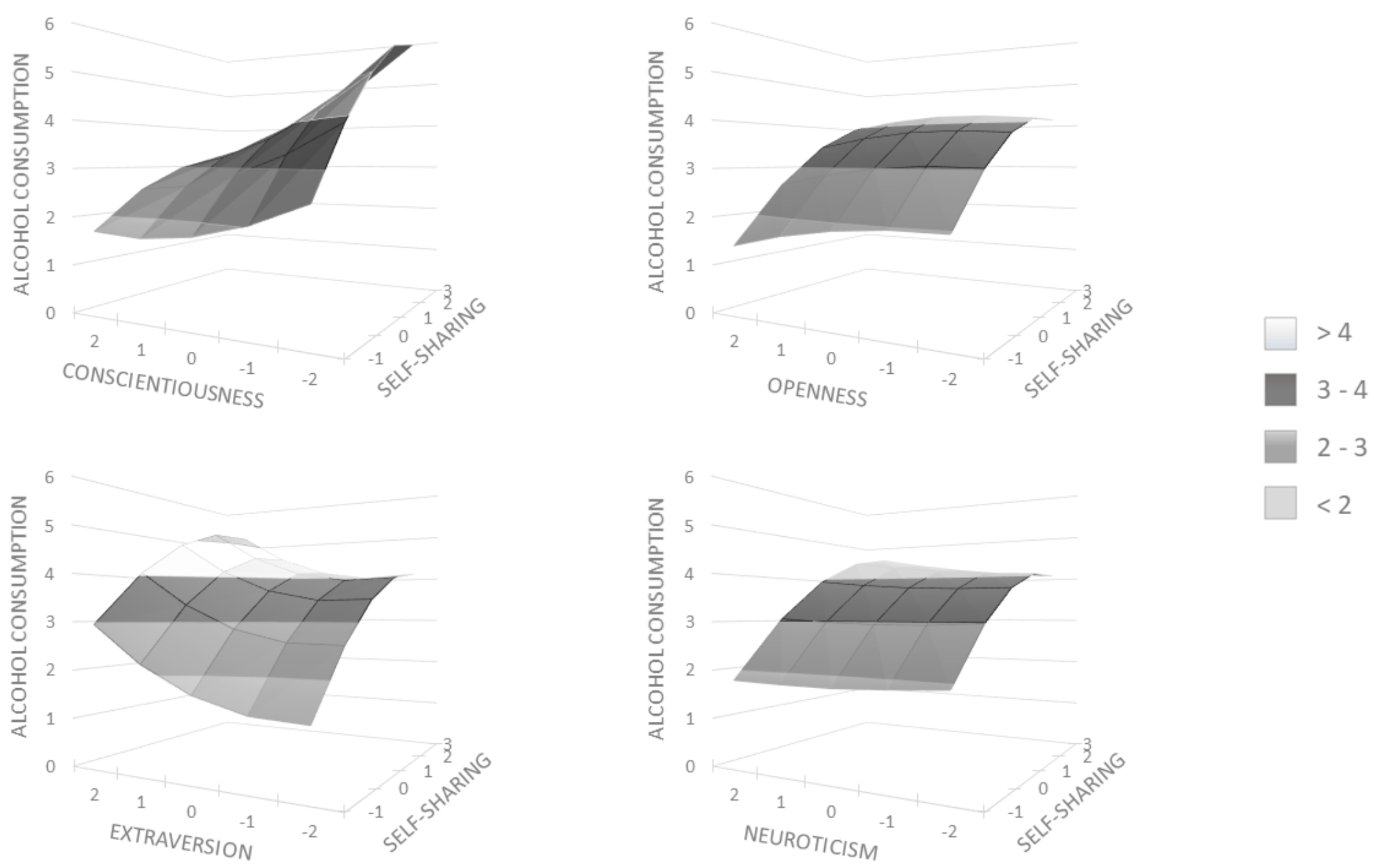

Note. All predictor and control variables are mean-centered $(M=0, S D=1) ;-1$ on the self-sharing scale equals not sharing

Figure 1. Response Surface Modeling of Alcohol Consumption as Predicted by Sharing Alcohol References on SNS and Personality 
BIG FIVE IN ALCOHOL-RELATED SOCIAL MEDIA EFFECTS 